\title{
A prospective comparison of perioperative morbidity in advanced epithelial ovarian cancer: Primary versus interval cytoreduction - experience from India Sheikh Zahoor Ahmad, Anupama Rajanbabu', D. K.Vijaykumar², Altaf Gauhar Haji, K. Pavithran³
}

\begin{abstract}
Objectives: The objective was to compare perioperative morbidity and mortality of patients with advanced epithelial ovarian cancer (EOC) treated with either of the two treatment approaches; neoadjuvant chemotherapy (NACT) followed by interval debulking versus upfront surgery. Design: Prospective comparative observational study. Participants: In total, 5 I patients were included in the study. All patients with diagnosed advanced EOC (International Federation of Gynecology and Obstetrics IIIC and IV) presenting for the $\mathrm{I}^{\text {st }}$ time were included in the study. Interventions: Patients were either operated upfront $(n=19)$ if deemed operable or were subjected to NACT followed by interval debulking $(n=32)$. Primary and Secondary Outcomes: Intra- and postoperative morbidity and mortality were the primary outcome measures. Results: Patients with interval cytoreduction were noted to have significantly lesser operative time, blood loss, and extent of surgery. Their discharge time was also significantly earlier. However, they did not differ from the other group vis. a vis. postoperative complications or mortality. Conclusions: Neoadjuvant chemotherapy although has a positive impact on various intraoperative adverse events, fails to show any impact on immediate postoperative negative outcomes.
\end{abstract}

Key words: Epithelial ovarian cancer, interval surgery, postoperative morbidity, primary surgery

\section{Introduction}

Ovarian cancer causes more deaths per year than any other cancer of the female reproductive system. ${ }^{[1]}$ Approximately, $90 \%$ of ovarian cancer is epithelial in origin and presents at an advanced stage. It is proven that debulking surgery removing the primary tumor and metastatic implants, achieving optimal debulking improves survival. ${ }^{[2]}$ Neoadjuvant chemotherapy (NACT) followed by interval cytoreduction (IC) has the advantage of reduced surgical morbidity and improved surgical cytoreduction. The present study examined the effect of NACT on peri-operative morbidity and evaluated various factors predictive of postoperative morbidity in this group.

\section{Methods}

This is a prospective observational study in which advanced epithelial ovarian cancer (EOC) (International Federation of Gynecology and Obstetrics [FIGO] IIIC and IV) patients, who underwent surgery at Amrita Institute of Medical Sciences at Kochi, Kerala, India from June 2008 to April 2010 were evaluated for intraoperative and immediate postoperative negative outcomes. All patients with FIGO stage I, II, IIIA and B ovarian cancers, and nonepithelial ovarian malignancies were excluded. The institutional review board cleared this study.

All patients with clinical features suggesting ovarian malignancy were evaluated with serum CA 125, abdominal imaging with ultrasonogram or computed tomography. Performance status (PS) was graded using the Eastern cooperative oncology group (ECOG) scale. All the cases were discussed in a multidisciplinary oncology tumor board. Patients with extensive disease seen on imaging and poor PS were considered for NACT, which was given only after histopathology or cytology confirmation of malignancy.

The aim of surgery was to achieve optimal debulking $(<1 \mathrm{~cm}$ residual disease). The patients who were planned for NACT received three or four cycles of chemotherapy before surgery. After surgery, patients were shifted to recovery rooms

\begin{tabular}{|l|}
\hline Access this article online \\
\hline Quick Response Code: \\
(a) \\
Website: www.sajc.org \\
\hline DOI: $10.4103 / 2278-330 X .173171$ \\
\hline
\end{tabular}

Department of Surgical Oncology,

Sheri-Kashmir Institute of Medical Sciences, Srinagar, Jammu and Kashmir, Departments of 'Gynecologic Oncology, ${ }^{2}$ Surgical Oncology and ${ }^{3}$ Medical Oncology, Amrita Institute of Medical Sciences, Amrita Vishwa Vidyapeetham, Kochi, Kerala, India

Correspondence to: Dr.Anupama Rajanbabu, E-mail: anupamashyam@gmail.com located adjacent to the operating theatre. Patients in need for intensive monitoring were shifted to Intensive Care Unit (ICU). They were shifted to the ward once hemodynamic stability and adequacy of respiration was ensured. Patients were discharged once they were physically fit and ambulatory.

The standard regime of chemotherapy was 3 weekly paclitaxel $\left(175 \mathrm{mg} / \mathrm{m}^{2}\right)$ given over 3 hours and carboplatin (area under the curve 6) given as an intravenous bolus. Patients with poor general condition were given only single agent chemotherapy (carboplatin/cisplatin).

Data regarding the patient (age, co-morbidities, ECOG PS, laboratory parameters), disease (date of diagnosis, stage, histopathology, grade), treatment received (initial treatment received, i.e., NACT vs. surgery, extent of surgery, duration of surgery, blood loss etc.), postoperative management, hospital stay and complications were recorded. Comorbidity was scored and categorized using a modification of the charlson comorbidity index (CCI). ${ }^{[3]}$ To assess the extent of surgical procedures, the surgical complexity score (SCS) described by Aletti et al. was adopted. ${ }^{[4]}$

All statistical analyses were performed using IBM Statistical Package for Social Sciences (SPSS) version 11. Comparison of categorical variables among groups was done with Chi-square test and continuous variables by Student's $t$-test. The complications, which were significantly different in incidence among the two treatment groups, were further evaluated by univariate analysis to look for other confounding variables. All statistical tests were two-tailed with a significance level set at $5 \%$.

\section{Results}

During the study period, out of the 196 patients of ovarian cancer registered in our Cancer Institute, 145 patients were excluded due to early stage $(n=35)$, operated outside $(n=73)$, nonepithelial histology $(n=24)$, and recurrent disease $(n=13) .51$ patients

This is an open access article distributed under the terms of the Creative Commons Attribution-NonCommercial-ShareAlike 3.0 License, which allows others to remix, tweak, and build upon the work non-commercially, as long as the author is credited and the new creations are licensed under the identical terms.

For reprints contact: reprints@medknow.com

How to cite this article: Ahmad SZ, Rajanbabu A, Vijaykumar DK, Haji AG, Pavithran K. A prospective comparison of perioperative morbidity in advanced epithelial ovarian cancer: Primary versus interval cytoreduction - experience from India. South Asian J Cancer 2015;4:107-10. 
satisfied our inclusion criteria. 19 patients were taken up for PS and 32 underwent IC after receiving NACT. Table 1 depicts the baseline characteristics of the two groups. The demographic and relevant baseline clinical characteristics of the patients were balanced between the two groups except for hemoglobin, which was significantly higher in the primary surgery group.

The comparative distribution of surgical complexity and various intra-operative complications are tabulated in Table 2. We were able to achieve residuum of $<2 \mathrm{~mm}$ in most cases. All patients in IC group were optimally cytoreduced, whereas 2 patients in the primary surgery were suboptimally cytoreduced.

The surgical procedures were scored based on the complexity of surgery (SCS) and grouped into three categories, low ( $\leq 3$ SCS), intermediate (4-7 SCS), and high ( $\geq 8$ SCS). As is noted in Table 2, higher proportion of patients undergoing PS had surgeries of intermediate/high grade, which were significantly longer. They also had significantly higher blood loss than IC group. Though the numbers of patients needing blood transfusion were similar, the number of units transfused was significantly higher in the primary surgery group.

Patients taken up for upfront surgery had a higher incidence of diaphragmatic injury and intra-operative hypotension needing inotropic support intra-operatively. None of the patients in IC group encountered similar complications.

The various postoperative characteristics and complications of the two groups are summarized in Table 3.1 patient in IC group and 2 patients in the PS group had adverse cardiac events postoperatively. The postoperative period was complicated by fever in $9(28 \%)$ and $6(31.5 \%)$ patients of IC and primary surgery group, respectively. 4 patients in each group developed respiratory complications $(P=0.459)$.

One patient in the IC group developed a leak from the appendicular stump, which improved with conservative

Table 1: Distribution of baseline characteristics in the two groups

\begin{tabular}{|c|c|c|c|}
\hline Baseline characteristic & $\begin{array}{c}\text { Interval } \\
\text { cytoreduction } \\
(n=32)\end{array}$ & $\begin{array}{c}\text { Primary } \\
\text { surgery } \\
(n=19)\end{array}$ & $P$ \\
\hline Mean age in years (SD) & $54.4(9.97)$ & $51.8(10.60)$ & 0.77 \\
\hline Mean hemoglobin in $\mathrm{g} / \mathrm{dl}$ (SD) & $10.8(1.01)$ & $11.9(1.43)$ & 0.007 \\
\hline Albumin in $\mathrm{g} / \mathrm{dl}(\mathrm{SD})$ & $4.02(0.35)$ & $3.92(0.51)$ & 0.422 \\
\hline $\mathrm{CA}-125$ in $\mathrm{U} / \mathrm{ml}(\mathrm{SD})$ & $2599(3065)$ & $3661(5775)$ & 0.865 \\
\hline $\mathrm{CCI}^{*}(n=51)$ & & & 1.0 \\
\hline 0 & 18 & 11 & \\
\hline$\geq 1$ & 14 & 8 & \\
\hline ECOG PS & & & 1.0 \\
\hline$\leq 1$ & 27 & 17 & \\
\hline$\geq 2$ & 4 & 2 & \\
\hline Histology & & & 1.0 \\
\hline Serous & 28 & 17 & \\
\hline Non-serous & 4 & 2 & \\
\hline Grade $(n=35)$ & & & 0.477 \\
\hline$\leq 2$ & 6 & 6 & \\
\hline 3 & 15 & 8 & \\
\hline FIGO stage & & & 1.0 \\
\hline IIIC & 26 & 16 & \\
\hline IV & 6 & 3 & \\
\hline \multicolumn{4}{|c|}{$\begin{array}{l}{ }^{*} \mathrm{CCI}=\text { Charlson comorbidity index, ECOG=Eastern cooperative oncology group, } \\
\mathrm{PS}=\text { Primary surgery, } \mathrm{SD}=\text { Standard deviation, FIGO=International Federation of } \\
\text { Gynecology and Obstetrics }\end{array}$} \\
\hline 108 & & & \\
\hline
\end{tabular}

management. 4 patients in each group had a superficial surgical site infection, managed with antibiotics and drainage wherever indicated $(P=0.459)$. None of the patients had fascial dehiscence or deep/organ space infection.

There was no significant difference in the duration of postoperative ileus, 1.97 days versus 2.26 days $(P=0.108)$ and postoperative antibiotic use, 6.07 versus 5 days $(P=0.885)$ in IC versus primary surgery group.

The mean ICU stay was 1.68 days (standard deviation [SD] $=2.11)$ in the primary surgery group and $0.97(\mathrm{SD}=1.9)$ days in the IC group $(P=0.107)$. The duration of hospital stay was significantly longer in primary surgery group (mean -8.11 days; $\mathrm{SD}=2.05$ ) as compared to $\mathrm{IC}$ group (mean -7.69 days; $\mathrm{SD}=10.75 ; P=0.001$ ). None of the patients in either group died within first 60 days after surgery.

The preoperative parameters of patients in two groups were similar except for preoperative hemoglobin, which was significantly lesser $(P=0.007)$ in the IC group as compared to primary surgery group [Table 3]. The two groups were otherwise balanced vis a vis age, CCI, PS, preoperative serum albumin, CA-125, histology, grade of tumor, and stage of disease [Table 1]. The SCS group, duration of surgery, operative blood loss, number of blood pints transfused, incidence of intra-operative hypotension, need for serosal disease debulking, risk of diaphragmatic injury, and duration of hospital stay was significantly higher in primary surgery group [Table 2]. On the other hand, variables like need for blood transfusion, duration of ICU stay, postoperative ileus, cardiac adverse events, postoperative fever, respiratory complications, surgical site infections, duration of postoperative antibiotics, and number of cultures sent in the two groups were not significantly different [Table 3].

Table 2: Surgical complexity and intra-operative parameters

\begin{tabular}{|c|c|c|c|}
\hline Characteristic & $\begin{array}{c}\text { Interval } \\
\text { cytoreduction } \\
(n=32)\end{array}$ & $\begin{array}{c}\text { Primary } \\
\text { surgery } \\
(n=19)\end{array}$ & $P$ \\
\hline SCG & & & 0.012 \\
\hline Low & 14 & 1 & \\
\hline Intermediate & 17 & 16 & \\
\hline High & 1 & 2 & \\
\hline Transfusion needed & & & 0.155 \\
\hline No & 16 & 6 & \\
\hline Yes & 14 & 13 & \\
\hline Serosal disease debulking & & & $<0.05$ \\
\hline No & 20 & 2 & \\
\hline Yes & 12 & 17 & \\
\hline Diaphragmatic injury & & & 0.047 \\
\hline No & 32 & 16 & \\
\hline Yes & 0 & 3 & \\
\hline Intra-operative hypotension & & & $<0.05$ \\
\hline No & 29 & 11 & \\
\hline Yes & 0 & 8 & \\
\hline $\begin{array}{l}\text { Mean operative time in } \\
\text { min (SD) }\end{array}$ & $289.14(110)$ & $390.79(111.8)$ & 0.004 \\
\hline $\begin{array}{l}\text { Mean intraoperative blood } \\
\text { loss in } \mathrm{ml}(\mathrm{SD})\end{array}$ & $433.10(249.9)$ & $763.15(452.2)$ & 0.005 \\
\hline $\begin{array}{l}\text { Mean number of blood } \\
\text { units transfused (SD) }\end{array}$ & $0.6(0.96)$ & $1.32(1.2)$ & 0.017 \\
\hline
\end{tabular}


Table 3: Distribution of various postoperative characteristics

\begin{tabular}{|c|c|c|c|}
\hline Characteristic & $\begin{array}{c}\text { Interval } \\
\text { cytoreduction } \\
(n=32)\end{array}$ & $\begin{array}{c}\text { Primary } \\
\text { surgery } \\
(n=19)\end{array}$ & $P$ \\
\hline $\begin{array}{l}\text { Mean duration of postoperative } \\
\text { ileus in days (SD) }\end{array}$ & $1.97(1.78)$ & $2.26(1.04)$ & 0.108 \\
\hline Mean ICU stay in days (SD) & $0.97(1.9)$ & $1.68(2.11)$ & 0.107 \\
\hline \multicolumn{4}{|l|}{ Cardiac events } \\
\hline No & 31 & 17 & 0.549 \\
\hline Yes & 1 & 2 & \\
\hline \multicolumn{4}{|l|}{ Postoperative fever } \\
\hline No & 23 & 13 & 1.0 \\
\hline Yes & 9 & 6 & \\
\hline \multicolumn{4}{|l|}{ Respiratory complications } \\
\hline No & 28 & 15 & 0.459 \\
\hline Yes & 4 & 4 & \\
\hline \multicolumn{4}{|l|}{ SSI } \\
\hline No & 28 & 15 & 0.459 \\
\hline Yes & 4 & 4 & \\
\hline \multicolumn{4}{|l|}{ Cultures if sent } \\
\hline No & 25 & 15 & 1.0 \\
\hline Yes & 7 & 4 & \\
\hline $\begin{array}{l}\text { Mean duration of postoperative } \\
\text { antibiotic in days (SD) }\end{array}$ & $6.07(8.98)$ & $5(3.9)$ & 0.885 \\
\hline Mean hospital stay in days (SD) & $7.69(10.75)$ & $8.11(2.05)$ & 0.001 \\
\hline
\end{tabular}

Since some variables analyzed were categorical and some continuous, for this reason, significant continuous variables were categorized into groups and tested again for significance. Thus, duration of surgery was grouped as $\leq 240 \mathrm{~min}$ and $>240 \mathrm{~min}$, operative blood loss as $\leq 500 \mathrm{ml}$ and $>500 \mathrm{ml}$, number of pints of blood transfused as $\leq 2$ and $>2$ and hospital stay as $\leq 7$ days and $>7$ days. These variables were again checked for significance after grouping using Chi-square test. Of these variables, operative blood loss was of borderline significance $(P=0.05)$ and number of pints of blood transfused came as insignificant $(P=0.28)$.

Univariate analysis of the predictors of intra-operative blood loss showed that operative time $>240$ min and serous histology were the only significant factors associated with increased blood loss. High preoperative hemoglobin levels and upfront surgery were of borderline significance $(P=0.05)$. Preoperative albumin levels, co-morbidity status, PS, grade of tumor, and surgical complexity group did not have any significant effect.

With regards to the predictors of intra-operative hypotension, only PS patients with increased blood loss during surgery had significantly higher incidence of intra-operative hypotension (respective $P<0.05$ and 0.001 ).

The univariate analysis of factors possibly predictive of duration of hospital stay showed patients having lower preoperative albumin levels $(P=0.02)$, upfront surgery $(P=0.01)$, longer operating hours $(P=0.01)$, more complex surgeries $(P=0.03)$, higher intra-operative blood loss $(P=0.03)$, need for blood transfusion $(P<0.05)$, and postoperative cardiac complications $(P=0.04)$, where the ones who were likely to have prolonged hospital stay. Notably, low preoperative hemoglobin levels, higher CCI, lower PS, elderly age, duration of ICU stay, and postoperative complications other than cardiac did not significantly prolong the hospital stay beyond 7 days.

South Asian Journal of Cancer • July-September 2015 • Volume 4 Issue 3

\section{Discussion}

The 5-year survival rates for EOC ranges from $80 \%$ to $15 \%$ for stages I-IV, respectively. ${ }^{[5]}$ The overall poor prognosis is due to advanced stage at presentation $(60-70 \%$ presenting at stage III/IV $)^{[6]}$ and low PS, precluding aggressive surgery. Women with advanced ovarian cancer who initiate systemic chemotherapy with an apparent small volume of residual disease after primary surgery experience a superior outcome compared to patients who cannot be optimally cytoreduced. ${ }^{[7]}$ Ultraradical surgery, with the addition of radical pelvic surgery, bowel resection, and removal of disease cephalad to the greater omentum, gave up to $91 \%$ optimal cytoreduction rates. ${ }^{[8]}$ However, morbidity of ultraradical surgery can be substantial, with serious operative and postoperative complications approaching $70 \% .{ }^{[9]}$ To overcome this problem, NACT followed by IC has been studied. Here the initial attempt at cytoreduction is abandoned in favor of chemotherapy in order to reduce the extent of disease and to improve patient PS. ${ }^{[10]}$

In our study, the preoperative characteristics of two groups were well matched, except for hemoglobin which was lower in NACT group, possibly an effect of chemotherapy. Incidence of serosal disease was more in primary surgery group as implied by "need for serosal disease debulking," which was significantly higher in this group. It was noted that patients in the primary surgery group underwent more complex procedures. The duration of surgery, blood loss, hypotension needing inotropic support, and number of blood pints transfused were significantly more in primary surgery group, pointing toward a presence of relatively larger quantum of disease in this group necessitating more extensive surgeries.

Despite all this, the incidence of postoperative complications was not significantly different among the two groups [Table 3]. The mean duration of ICU stay was not significantly different among the two groups, but patients undergoing primary surgery took longer time till discharge (mean $=8.11$ days; $\mathrm{SD}=2.05$ ) than IC (mean $=7.69$ days; $\mathrm{SD}=10.75 ; P=0.001$ ). There were no postoperative deaths in our study. Results similar to ${ }^{[11-13]}$ and contradicting ${ }^{[14,15]}$ our study have been reported. This study suffers from a small sample size, which might be the reason behind its failure to capture the difference in the postoperative complications; however its prospective design eliminates the biases associated with retrospective studies.

Vergote et al. ${ }^{[16]}$ had demonstrated noninferiority of NACT approach over primary surgery. Although they reported relatively lesser postoperative complications and mortality in the NACT arm, inferential analysis was not performed, as all the patients randomized to each arm did not receive their allotted treatment. They did not find any significant difference in the quality of life scores among the two arms, at any point of assessment.

\section{Conclusion}

Ours is first study from India, which has looked into the effect of NACT on immediate negative postoperative outcomes in patients with advanced EOC. Moreover, this study has demonstrated the favorable effect of NACT on variables like the complexity of surgery, duration of surgery, blood loss, intraoperative hypotension, and hospital stay. There is likely to be a cost implication of this, with the reduced cost favoring NACT group. This would 
be a good reason to consider NACT as the first line therapy in advanced ovarian cancers, especially in low-resource settings.

\section{Acknowledgments}

Mr. Sundaram and Ms. Amrutha of Department of Biostatistics of Amrita School of Medicine, Kochi, Kerala, India. Dr. K Chitrathara, Dr. Shekhar Sharma, Dr. Santhosh Kuriakose, Dr. Tejal Gorasia and Dr. Dhiraj Khadakban of Department of Surgical Oncology at Amrita Institute of Medical Sciences.

\section{Financial support and sponsorship}

Nil.

\section{Conflicts of interest}

There are no conflicts of interest.

\section{References}

1. Wey JP, Sellers TA. Epidemiology of ovarian cancer. Methods Mol Biol 2009;472:413-37.

2. Cannistra SA. Cancer of the ovary. N Engl J Med 2004;351:2519-29.

3. Charlson ME, Pompei P, Ales KL, MacKenzie CR. A new method of classifying prognostic comorbidity in longitudinal studies: Development and validation. J Chronic Dis 1987;40(5):373-83.

4. Aletti GD, Santillan A, Eisenhauer EL, Hu J, Aletti G, Podratz KC, et al. A new frontier for quality of care in gynecologic oncology surgery: Multi-institutional assessment of short-term outcomes for ovarian cancer using a risk-adjusted model. Gynecol Oncol 2007; 107:99-106.

5. Pectasides D, Farmakis D, Koumarianou A. The role of neoadjuvant chemotherapy in the treatment of advanced ovarian cancer. Oncology 2005;68:64-70.

6. Pecorelli S, Favalli G, Zigliani L, Odicino F. Cancer in women. Int J Gynaecol Obstet 2003;82:369-79.
7. Griffiths CT. Surgical resection of tumor bulk in the primary treatment of ovarian carcinoma. Natl Cancer Inst Monogr 1975;42:101-4.

8. Covens AL. A critique of surgical cytoreduction in advanced ovarian cancer. Gynecol Oncol 2000;78:269-74.

9. Chi DS, Zivanovic O, Levinson KL, Kolev V, Huh J, Dottino J et al. The incidence of major complications after the performance of extensive upper abdominal surgical procedures during primary cytoreduction of advanced ovarian, tubal, and peritoneal carcinomas. Gynecol Oncol 2010;119(1):38-42.

10. Bristow RE, Eisenhauer EL, Santillan A, Chi DS. Delaying the primary surgical effort for advanced ovarian cancer: A systematic review of neoadjuvant chemotherapy and interval cytoreduction. Gynecol Oncol 2007; 104:480-90.

11. Schwartz PE, Rutherford TJ, Chambers JT, Kohorn El, Thiel RP. Neoadjuvant chemotherapy for advanced ovarian cancer: Long-term survival. Gynecol Oncol 1999;72(1):93-9.

12. Hegazy MA, Hegazi RA, Elshafei MA, Setit AE, Elshamy MR, Eltatoongy $\mathrm{M}$, et al. Neoadjuvant chemotherapy versus primary surgery in advanced ovarian carcinoma. World J Surg Oncol 2005;3:57.

13. Hou JY, Kelly MG, Yu H, McAlpine JN, Azodi M, Rutherford TJ, et al. Neoadjuvant chemotherapy lessens surgical morbidity in advanced ovarian cancer and leads to improved survival in stage IV disease. Gynecol Oncol 2007; 105:211-7.

14. Morice P, Dubernard G, Rey A, Atallah D, Pautier P, Pomel C, et al. Results of interval debulking surgery compared with primary debulking surgery in advanced stage ovarian cancer. J Am Coll Surg 2003;197:955-63.

15. Colombo PE, Mourregot A, Fabbro M, Gutowski M, Saint-Aubert B, Quenet $F$, et al. Aggressive surgical strategies in advanced ovarian cancer: A monocentric study of 203 stage IIIC and IV patients. Eur J Surg Oncol 2009;35:135-43.

16. Vergote I, Tropé CG, Amant F, Kristensen GB, Ehlen T, Johnson N, et al. Neoadjuvant chemotherapy or primary surgery in stage IIIC or IV ovarian cancer. N Engl J Med 2010;363:943-53.

\section{Author Help: Online submission of the manuscripts}

Articles can be submitted online from http://www.journalonweb.com. For online submission, the articles should be prepared in two files (first page file and article file). Images should be submitted separately.

1) First Page File:

Prepare the title page, covering letter, acknowledgement etc. using a word processor program. All information related to your identity should be included here. Use text/rtf/doc/pdf files. Do not zip the files.

2) Article File:

The main text of the article, beginning with the Abstract to References (including tables) should be in this file. Do not include any information (such as acknowledgement, your names in page headers etc.) in this file. Use text/rtf/doc/pdf files. Do not zip the files. Limit the file size to $1 \mathrm{MB}$. Do not incorporate images in the file. If file size is large, graphs can be submitted separately as images, without their being incorporated in the article file. This will reduce the size of the file.

3) Images:

Submit good quality color images. Each image should be less than $4096 \mathrm{~kb}(4 \mathrm{MB})$ in size. The size of the image can be reduced by decreasing the actual height and width of the images (keep up to about 6 inches and up to about $1800 \times 1200$ pixels). JPEG is the most suitable file format. The image quality should be good enough to judge the scientific value of the image. For the purpose of printing, always retain a good quality, high resolution image. This high resolution image should be sent to the editorial office at the time of sending a revised article.

4) Legends:

Legends for the figures/images should be included at the end of the article file. 